\title{
A Retrospective Review of Factors Associated with Vasovasostomies in United States Military Members
}

\author{
Masterson Ja $\quad$ Avalos $\mathrm{E}^{\mathrm{b}} \quad$ Santomauro $\mathrm{M}^{\mathrm{a}} \quad$ Walters $\mathrm{R}^{\mathrm{c}}$ \\ Marguet $C^{d} \quad$ L'Esperance Ja $^{\mathrm{a}} \quad$ Crain Da
}

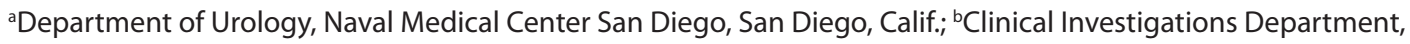
Naval Medical Center San Diego, San Diego, Calif.; 'Department of Urology, Naval Medical Center, Portsmouth, Va.; dUniversity Medical Group, Regional Urology, Greenville, .S.C., USA

\section{Key Words}

Vasovasostomy • Vasectomy counseling • Demographics • Infertility

\begin{abstract}
Background: Men seeking a vasectomy should receive counseling prior to the procedure that includes discussion of later seeking a reversal. We sought to determine demographic factors that may predispose patients to possibly later seek a vasectomy reversal. Methods: All U.S. Military electronic health records were searched between 2000 and 2009 for either a vasectomy or vasovasostomy procedure code. Aggregate demographic information was collected and statistical analysis performed. Result: A total of 82,945 patients had a vasectomy of which 4,485 had a vasovasostomy resulting in a vasovasostomy-to-vasectomy rate of $5.04 \%$. The average age at vasovasostomy was $34.9 \pm 5.0$, with an average interval of $4.1 \pm 2.2$ years. Men undergoing a vasectomy at a younger age were more likely to have a vasovasostomy. Various religions did have statistically significant differences. Within ethnic groups, only Native Americans [OR=1.39 (95\% $\mathrm{Cl} 1.198-1.614)]$ and Asians [OR=0.501 (95\% Cl 0.364-0.690)] had statistically significant differences when compared to Caucasians. Men with more children at the time of vasectomy were more likely to have a vasovasostomy. Conclusion: Younger men, Native Americans, and men with more chil-
\end{abstract}

\section{KARGER}

Fax +4161306 1234 E-Mail karger@karger.ch www.karger.com dren at vasectomy were more likely to undergo a vasovasostomy. The reason for these differences is unknown, but this information may assist during pre-vasectomy counseling.

Copyright $\odot 2012$ S. Karger AG, Basel

\section{Introduction}

Vasectomy is the primary form of contraception in 33 million men between the ages 15 and 49 years worldwide [1]. Vasectomy is the safest and most inexpensive option for permanent sterilization, with long-term failure rates less than $1 \%$ [2-4]. Historically, up to $6 \%$ of men will request a vasectomy reversal after undergoing a vasectomy [5-7]. A vasovasostomy is the most common form of vasectomy reversal, but it is a labor-intensive operation requiring 2 to 4 hours to complete [8]. The cost per pregnancy in 2005 per surgical vasectomy reversal was estimated to be $\$ 20,903$ which factors the cost of the procedure, indirect cost of complications, and lost productivity [9]. As a comparison, the cost of pregnancy after testicular sperm extraction was $\$ 54,797$ [9]. 
Even though vasectomies are an efficient and relatively quick procedure, physicians should counsel patients on factors that may later lead to seeking a reversal. Young age at vasectomy is a known risk factor with vasectomies performed between the ages of 20 and 24 having a reported $13 \%$ reversal rate [10]. Remarriage to a nulliparous partner is also a predictive factor as well as feeling pressured to undergo the initial vasectomy due to his partner's health or upon his doctor's recommendation $[5,10]$. Factors that have not been adequately studied include race, religion, interval versus age, number of children, and the interval of waiting before undergoing a reversal.

The United States military provides an equal access health care system [11]. Without the potentially prohibitive cost of a vasectomy reversal, patient characteristics can easily be studied to determine factors that may be associated with a request for a vasectomy reversal [12]. Better knowledge of these characteristics can improve pre-procedural counseling for men considering a vasectomy.

\section{Methods}

With Institutional Review Board approval, a retrospective study was performed using the Career History Archival Medical and Personnel System (CHAMPS). The CHAMPS database contains longitudinal data on all active duty military personnel from time of entry to time of discharge. Demographic characteristics and dates of both inpatient and outpatient surgical procedures are collected within this database [13].

We screened the CHAMPS database for all men who had undergone a vasectomy-CPT code 55250, as well as all men who had undergone a vasovasostomy-CPT code 55400 from 2000 to 2009. The age at vasectomy, age at vasovasostomy, religion, race, and number of dependents were recorded (table 1). The time interval between vasectomy and vasovasostomy for men who had both procedures during the time period was also obtained.

The data were organized into specific groups. The religions listed were Jehovah Witness, Baptist, Catholic, Mormon, other Protestant, Muslim, Jewish, Buddhist/Hindu, Atheist, no preference, Wicca, and Unknown. The races were Asian, Black, Native American, Pacific Islander, Caucasian, and Other. Of note, CHAMPS does not differentiate Hispanic as a separate ethnic group. Age was examined as a continuous variable and also categorically by using the following age-groups: 20-24 years, 25-29 years, 30-34 years, 35-39 years, and 40+ years.

Information was collected on the number of children and whether or not the patient was married at the time of vasectomy reversal. For patients that had both a vasovasostomy and vasectomy during the 10-year period, the average wait time for each age group was calculated based upon their age group.

Means and rates were calculated for continuous and categorical demographic variables. Comparisons of individuals with and without vasovasostomy were performed. Results were expressed as odds ratios (ORs) with $95 \%$ confidence intervals (CIs). Unadjusted univariate associations of each covariate as a predictor of vasovasostomy were examined. All $p$-values are two-sided; $p \leq$ 0.05 was considered statistically significant. All data manipulation and analyses were conducted using Statistical Analysis Software (Version 9.1.3, 2006, SAS Institute, Inc., Cary, NC, USA).

\section{Results}

A total of 4,485 vasectomy reversals and 82,945 vasectomies were captured in the CHAMPS database from 2000 to 2009. This results in an overall vasovasostomy rate per vasectomy of $5.4 \%$. The average age of men undergoing a vasectomy was $32.6 \pm 5.7$ years. Men undergoing vasovasostomy had an average age of $34.9 \pm 5.0$ years. The average time period between vasectomy and vasovasostomy for men that had both procedures within the studied time period was $4.13 \pm 2.2$ years. The average number of children was 1.35 for men undergoing a vasectomy and 1.16 for men undergoing a vasovasostomy.

Younger men, 20-24 years and 25-29 years of age were 1.56 times (95\%CI 1.27-1.91) and 1.70 times (95\% CI 1.45-1.98) more likely to later seek a vasovasostomy, respectively (table 2). Younger patients, at the time of vasectomy, were more likely to wait a longer time interval before undergoing a vasectomy reversal (fig. 1); on average, men in the 20 -to- 25 year-old age range waited 4.6 years to have a vasovasostomy compared to men in the 41-to-46 year-old age range, who waited roughly 2.0 years.

Protestants, with the largest segment of the population, with a rate of occurrence of $5.4 \%$, were set as the reference. Religious preference was a statistically significant predictor of vasovasostomy in Muslims and Baptists, whereas men without a religious preference were significantly less likely to have a vasovasostomy (fig. 2). Men who identified as Muslim, compared to men who identified as Protestant, were almost twice as likely [OR $=1.90$ (95\% CI 1.11-3.24)], to have a vasovasostomy. Men who identified as Baptist, compared to men who identified as Protestant, were $15 \%$ more likely [OR $=1.15$ (95\% CI 1.06-1.26)], to have a vasovasostomy. In contrast, compared to men who identified as Protestant, men who identified as having no religious preference were $13 \%$ less likely $[\mathrm{OR}=0.879$ (95\% CI 0.802-0.964)], to have a vasovasostomy.

Regarding race (table 2), men who identified as Asian, compared to men who identified as Caucasian were $50 \%$ less likely $[\mathrm{OR}=0.50(95 \%$ CI $0.36-0.69)]$, to have a 
Table 1. Demographic characteristics of patients

\begin{tabular}{|c|c|c|}
\hline Variable & Vasectomy & Vasovasostomy \\
\hline Age (year) & $32.62 \pm 5.67$ & $34.92 \pm 5.01$ \\
\hline \multicolumn{3}{|l|}{ Race } \\
\hline Asian & $1,454(1.81 \%)$ & $39(0.90 \%)$ \\
\hline Black & $11,881(14.78 \%)$ & $635(14.68 \%)$ \\
\hline Caucasian & $62,880(78.24 \%)$ & $3,366(77.83 \%)$ \\
\hline Native American & $2,646(3.29 \%)$ & $197(4.55)$ \\
\hline Pacific Islander & $1,504(1.87 \%)$ & $88(2.03 \%)$ \\
\hline \multicolumn{3}{|l|}{ Religion } \\
\hline Atheist & $307(0.39 \%)$ & $12(0.28 \%)$ \\
\hline Baptist & $15,608(19.94 \%)$ & $967(22.70 \%)$ \\
\hline Buddhist/Hindu & $210(0.27 \%)$ & $13(0.31 \%)$ \\
\hline Catholic & $17,794(22.73 \%)$ & $971(22.80 \%)$ \\
\hline Jehovah's Witness & $27(0.03 \%)$ & $1(0.02 \%)$ \\
\hline Jewish & $242(0.31 \%)$ & $11(0.26 \%)$ \\
\hline Muslim & $147(0.19 \%)$ & $15(0.35 \%)$ \\
\hline Mormon & $1,468(1.88 \%)$ & $87(2.04 \%)$ \\
\hline No preference & $14,917(19.06 \%)$ & $704(16.53 \%)$ \\
\hline Protestant & $27,402(35.01 \%)$ & $1,471(34.54 \%)$ \\
\hline Wicca & $148(0.19 \%)$ & $7(0.16 \%)$ \\
\hline \multicolumn{3}{|l|}{ Number of Children } \\
\hline 0 & $23,755(33.41 \%)$ & $1,251(30.71 \%)$ \\
\hline 1 & $15,721(22.11 \%)$ & $625(15.34 \%)$ \\
\hline 2 & $19,100(26.86 \%)$ & $978(24.01 \%)$ \\
\hline 3 & $9,152(12.87 \%)$ & $826(20.27 \%)$ \\
\hline 4 & $2,552(3.59 \%)$ & $278(6.82 \%)$ \\
\hline $5+$ & $820(1.15 \%)$ & $116(2.85 \%)$ \\
\hline \multicolumn{3}{|l|}{ Service } \\
\hline Air Force & $25,086(30.24 \%)$ & $1,412(31.48 \%)$ \\
\hline Army & $30,290(36.52 \%)$ & $1,971(43.95 \%)$ \\
\hline Coast Guard & $1,412(1.70 \%)$ & $88(1.96 \%)$ \\
\hline Navy & $18,631(22.46 \%)$ & $735(16.39 \%)$ \\
\hline Marine Corps & $7,526(9.07 \%)$ & $279(6.22 \%)$ \\
\hline
\end{tabular}

vasectomy reversal. Whereas Native American men, compared to Caucasian men were 39\% more likely [OR $=1.39$ (95\% CI 1.20-1.61)], to have a vasovasostomy. A direct relationship was seen between the number of children and the rate of vasovasostomy. Men reporting having one child at time of vasectomy were 22\% [OR $=0.78$ (95\% CI 0.70-0.86)] less likely to have a vasovasostomy compared to men who had two children at vasectomy. Conversely, men reporting having 3, 4 or 5 or more children at vasectomy were 1.76 times $(95 \% \mathrm{CI}$
Table 2. Univariate analysis of potential predictors of vasovasostomy

\begin{tabular}{|c|c|c|}
\hline Predictor & OR (95\%CI) & $\mathrm{p}$ \\
\hline \multicolumn{3}{|l|}{ Age (year) } \\
\hline 20 to 24 & $1.557(1.272-1.906)$ & 0.1240 \\
\hline 25 to 29 & $1.698(1.454-1.984)$ & 0.0074 \\
\hline 30 to 34 & - & - \\
\hline 35 to 39 & $0.488(1.454-1.984)$ & 0.0111 \\
\hline $40+$ & $0.255(0.173-0.377)$ & 0.0058 \\
\hline \multicolumn{3}{|l|}{ Race } \\
\hline Asian & $0.501(0.364-0.690)$ & $<0.0001$ \\
\hline Black & $0.998(0.915$ to 1.089$)$ & 0.9718 \\
\hline Caucasian & - & - \\
\hline Native American & $1.391(1.198-1.614)$ & $<0.0001$ \\
\hline Pacific Islander & $1.093(0.879-1.359)$ & 0.4233 \\
\hline \multicolumn{3}{|l|}{ Religion } \\
\hline Atheist & $0.728(0.408-1.299)$ & 0.2829 \\
\hline Baptist & $1.154(1.062-1.255)$ & 0.0008 \\
\hline Buddhist/Hindu & $1.153(0.657-2.024)$ & 0.6196 \\
\hline Catholic & $1.017(0.935-1.105)$ & 0.6996 \\
\hline Jehovah's Witness & $0.690(0.094-5.081)$ & 0.7156 \\
\hline Jewish & $0.847(0.462-1.553)$ & 0.5908 \\
\hline Muslim & $1.901(1.115-3.242)$ & 0.0183 \\
\hline Mormon & $1.104(0.884$ to 1.379$)$ & 0.3836 \\
\hline No preference & $0.879(0.802-0.964)$ & 0.0061 \\
\hline Protestant & - & - \\
\hline Wicca & $0.881(0.412-1.884)$ & 0.7313 \\
\hline \multicolumn{3}{|l|}{ Number of Children } \\
\hline 0 & $1.028(0.944-1.121)$ & 0.5212 \\
\hline 1 & $0.776(0.701-0.860)$ & $<0.0001$ \\
\hline 2 & - & - \\
\hline 3 & $1.763(1.601-1.940)$ & $<0.0001$ \\
\hline 4 & $2.127(1.850-2.446)$ & $<0.0001$ \\
\hline $5+$ & $2.763(2.251-3.391)$ & $<0.0001$ \\
\hline \multicolumn{3}{|l|}{ Service } \\
\hline Air Force & $0.865(0.806-0.928)$ & $<0.0001$ \\
\hline Army & - & - \\
\hline Coast Guard & $0.958(0.769-1.194)$ & 0.7008 \\
\hline Navy & $0.606(0.556-0.661)$ & $<0.0001$ \\
\hline Marine Corps & $0.570(0.501-0.647)$ & $<0.0001$ \\
\hline
\end{tabular}

1.60-1.94), 2.12 times (1.85-2.45) and 2.76 times (95\% CI 2.25-3.39) more likely to have a vasectomy reversal compared to men who had 2 children at vasectomy.

\section{Discussion}

Vasectomy is an efficacious and safe form of sterilization that can be performed in an outpatient setting [1]. Although a vasectomy is considered "permanent", 


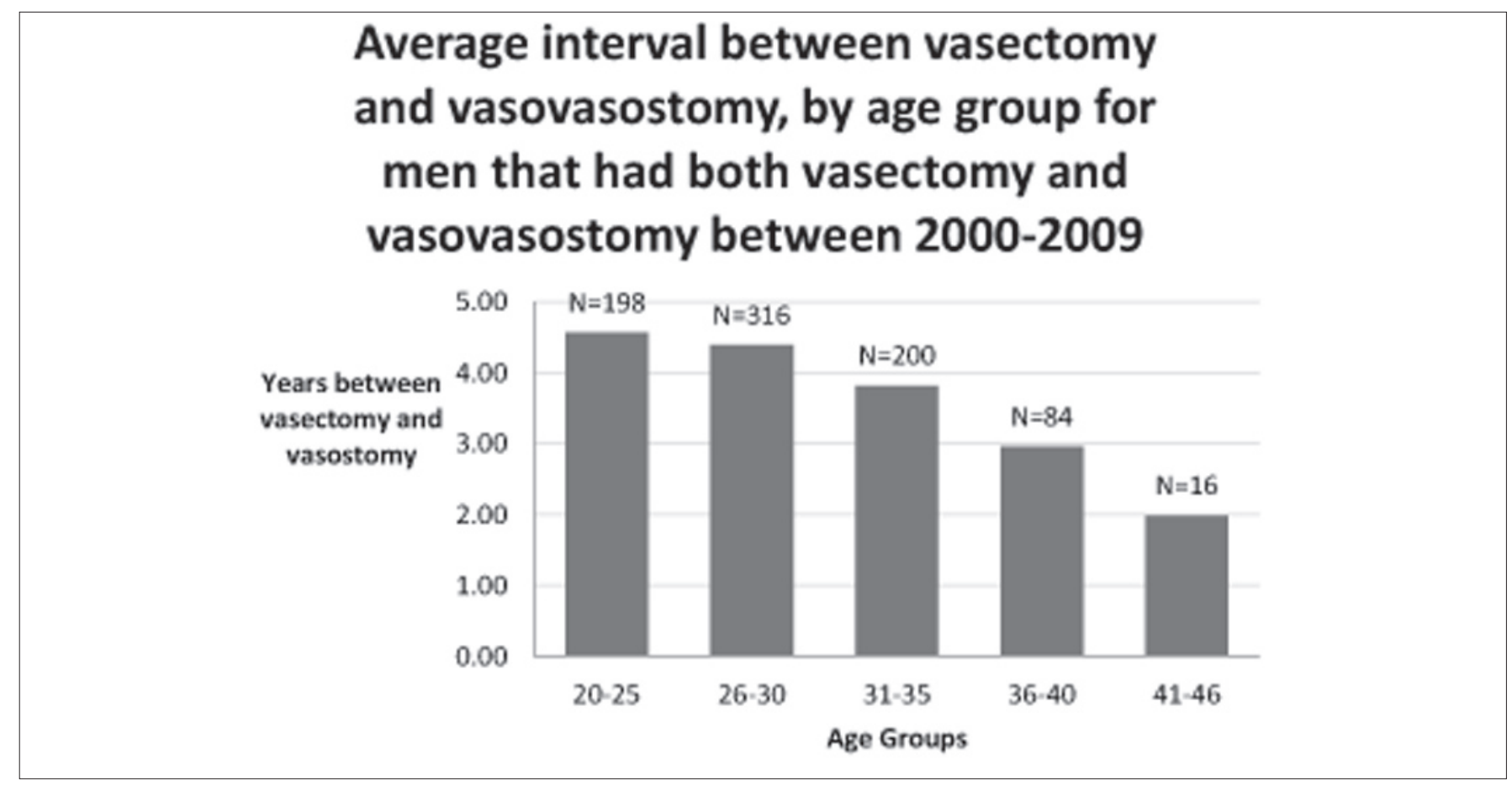

Fig. 1. Even though men who had a vasectomy at a younger age were more likely to seek a reversal, they were also more likely a wait longer before undergoing a vasovasostomy.

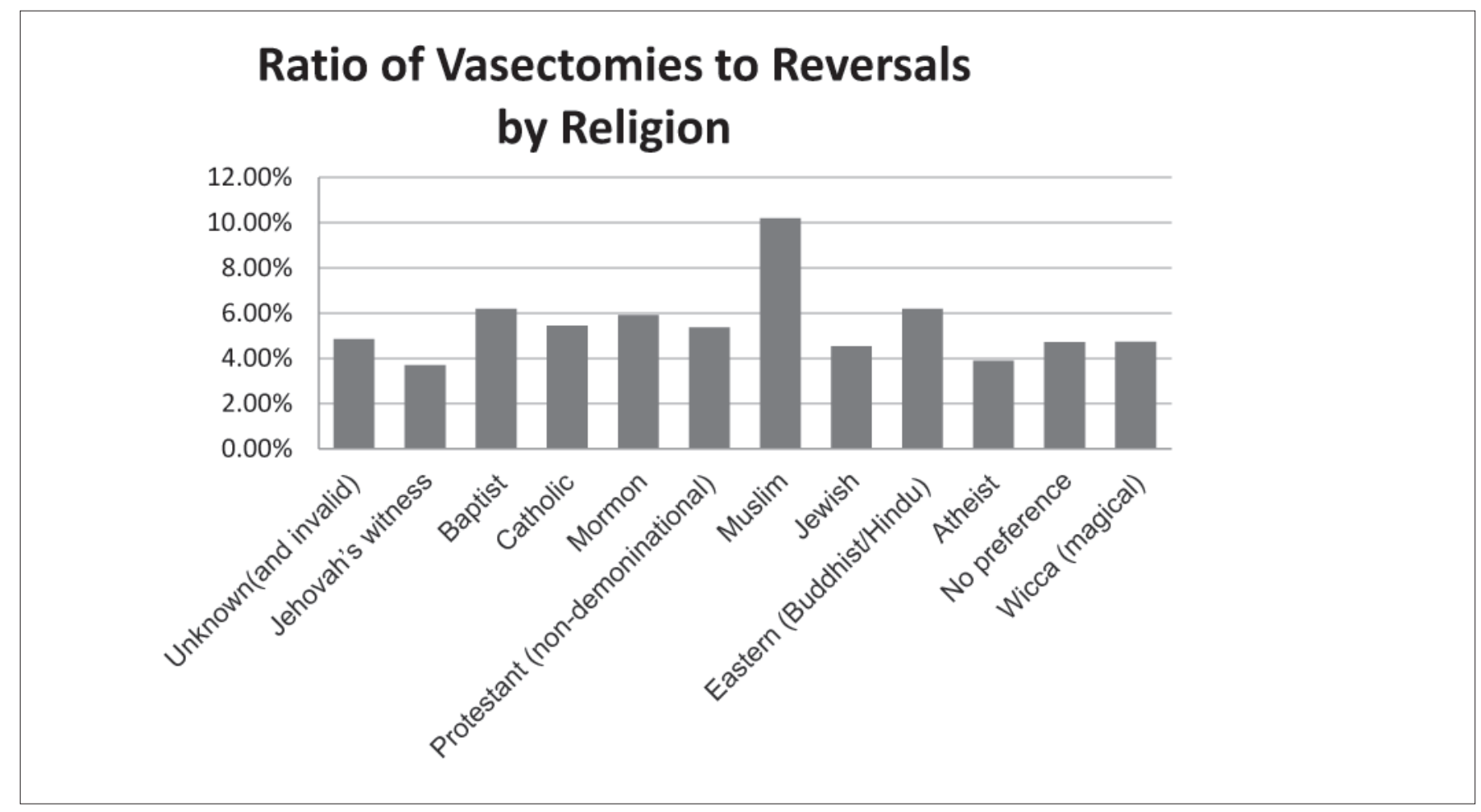

Fig. 2. In this chart the Muslim religion is noted to have a much higher rate of reversal than the other religions and Atheists are noted to have the lowest. 
approximately $6 \%$ of men will eventually seek a vasectomy reversal [5-7]. Vasectomy reversals are offered in the current military system but require general anesthesia and reserved time in the operating room. Beneficiaries to the military health care system receive care without personal expense; this allows evaluation of the demographics and decision process without financial undertones. We sought to use this unique system to evaluate factors predisposing patients who have had a vasectomy to later seek a vasectomy reversal.

Howard et al. [10] cite remarriage as a common inciter of men seeking a vasectomy reversal. Unfortunately, this information is of little use to a pre-vasectomy counselor because the male patient generally has not yet remarried, and likely is not considering that option at the time of vasectomy. Our study is directed to discover pre-vasectomy factors that may later influence or effect a decision to have a reversal. The incidence of vasectomy reversal of $5.4 \%$ shown here is similar to that reported in previous series [5-7]. However, this number may be an underestimate since men may seek vasectomy reversal after leaving active duty service or may be stationed in locations where vasectomy reversal is not offered, and they may seek care in the civilian community.

The results of this study corroborate earlier studies that show younger men are more likely to seek a reversal [5, 10]. Reasons postulated by previous studies have been: higher likelihood of divorce and remarriage, immaturity, altered attitude toward family size, and improved financial situation $[5,14-16]$. What has also not been studied is the time men wait before having a reversal. In our study men who underwent a vasectomy at an older age and later sought a reversal were more likely to undergo a reversal in a shorter time span than their younger counterparts. We can only speculate that this may be due to an older female partner desiring fertility. If she desires a child, she may apply pressure to her male partner to seek a reversal more quickly.

Our study showed that Asians were less likely and Native Americans were more likely to have a reversal.

Muslims also appeared more likely to seek a reversal, which may be due to several relatively recent religious rulings regarding vasectomies. Ten to twenty years ago, several religious leaders had allowed vasectomies, citing that it was reversible. Recently, however, religious leaders have spoken against vasectomies [17]. Muslims who have had a vasectomy prior to the religious rulings may sense a religious responsibility to correct a now-forbidden procedure by undergoing a reversal.
Contrary to common perception, our study showed that the more children a man had, the more likely he was to seek a reversal. This aspect has not been explored or discussed during our literature review, but anecdotally in our practice, most men who undergo a vasectomy reversal usually already have at least 2 children. This information can potentially assist the patient's decision process by making them aware that simply having more children doesn't reduce the likelihood of later seeking reversal.

As with any retrospective study of a large database, there are several limitations to note about this study. Over a 10-year period, the studied population may have had changes which would skew our data. The CHAMPS database also does not capture men who had a vasectomy or vasovasostomy prior to joining or after leaving the military. In regards to the number of children, this does not consider adopted children or marriage to a woman who already has children. Due to limitations of the CHAMPS database, information on number of marriages, age at marriage, or number of divorces was not available to the investigators.

\section{Conclusion}

Certain factors appear to be associated with a higher likelihood of patients undergoing a vasovasostomy, including: young age at vasectomy, Native American race, increased number of children, Baptist religion and Muslim religion. The reason behind these differences is unknown, but may be studied through further prospective or qualitative future research. This information may assist the pre-vasectomy counselor in discussing the procedure with patients seeking a vasectomy.

\section{Acknowledgements}

We would like to thank Dr Van Orden, Dr Crum-Cianflone, and members of their team, Thierry Nedellec and Robin HighfillMcRoy, located at the Naval Health Research Center (NHRC) for data preparation.

The views expressed in this article are those of the authors and do not reflect the official policy or position of the Department of the Navy, Department of Defense, or the United States Government. 


\section{References}

1 Pile JM, Barone MA: Demographics of vasectomy-USA and international. Urol Clin North Am 2009;36:295-305.

2 Dassow P, Bennett JM: Vasectomy: an update. Am Fam Physician 2006;74:2069_ 2074.

3 Hendry WF: Vasectomy and vasectomy reversal. Br J Urol 1994;73:337-344.

4 Schwingl PJ, Guess HA: Safety and effectiveness of vasectomy. Fertil Steril 2000;73:923 936.

5 Potts JM, Pasqualotto FF, Nelson D, Thomas AJ Jr, Agarwal A: Patient characteristics associated with vasectomy reversal. J Urol 1999;161:1835-1839.

-6 Goldstein M: Vasectomy reversal. Compr Ther 1993;19:37-41.
7 The Practice Committee of the American Society for Reproductive Medicine: Vasectomy reversal. Fertil Steril 2004;82(suppl 1): S194-S198.

8 Brandell RA, Goldstein M: Vasectomy reversal. Compr Ther 2000;26:39-43.

9 Robb P, Sandlow JI: Cost-effectiveness of vasectomy reversal. Urol Clin North Am $>15$ Clarke L, Gregson S: Who has a vasectomy 2009;36:391-396.

10 Howard G: Who ask for vasectomy reversal and why? Br Med J (Clin Res Ed) 1982;285: 490-492.

11 Miles D: Health plan to remain free for troops, Officials emphasize. American Forces Press Service, January 7, 2011.

12 Costabile RA, Spevak M: Characterization of patients presenting with male factor infertility in an equal access, no cost medical system. Urology 2001;58:1021-1024.
13 Gorham ED, Garland FC, Millar M, Gunderson EK: The Career History Archival Medical and Personnel System (CHAMPS): an epidemiological data resource for force health protection. RTO-MP-HFM-108, 2004.

14 Howards SS: Vasovasotomy. Urol Clin North Am 1980;7:165-169.

\section{reversal? J Biosoc Sci 1986;18:253-259.}

16 Shah ZH, Ganta SB, Morgans BT: The trends of vasectomy reversal in the forces. J R Army Med Corps 2003;149:265-266. fatwa may inform a muslim patient's surgical options. ANZ J Surg 2009;79:866-871.
17 Black A: Fatwas and surgery: how and why a 